
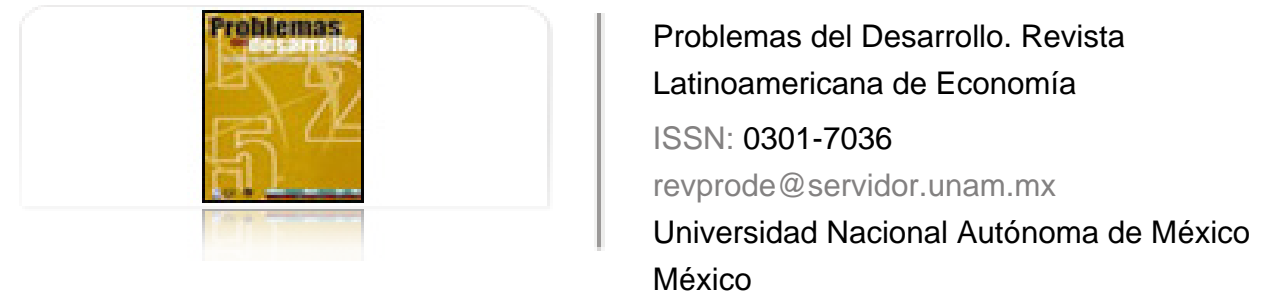

Puyana Mutis, Alicia; Romero Tellaeche, José Antonio La maquila (fragmentación de los procesos productivos) y su impacto sobre las remuneraciones a los factores

Problemas del Desarrollo. Revista Latinoamericana de Economía, vol. 36, núm. 141, abril-junio, 2005, pp. $155-182$

Universidad Nacional Autónoma de México

Distrito Federal, México

Disponible en: http://www.redalyc.org/articulo.oa?id=11820075009

- Cómo citar el artículo

- Número completo

- Más información del artículo

Página de la revista en redalyc.org

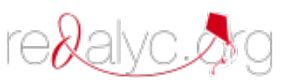

Sistema de Información Científica

Red de Revistas Científicas de América Latina, el Caribe, España y Portugal Proyecto académico sin fines de lucro, desarrollado bajo la iniciativa de acceso abierto 


\title{
LA MAQUILA (FRAGMENTACIÓN DE LOS PROCESOS PRODUCTIVOS) Y SU IMPACTO SOBRE LAS REMUNERACIONES A LOS FACTORES
}

\author{
Alicia Puyana Mutis* \\ José Antonio Romero Tellaeche**
}

Fecha de recepción: 4 de noviembre de 2004. Fecha de aceptación: 29 de abril de 2005.

Resumen

La maquila de programa temporal de empleo devino en permanente, como estrategia para acelerar el crecimiento industrial. Después de tres décadas de existencia, sus efectos en la productividad, la integración de valor agregado nacional y el crecimiento de todo el sector manufacturero no cumplen lo esperado. Los factores que explican este resultado son la operación de los estímulos otorgados por los gobiernos de Estados Unidos y de México; la racionalidad económica de la fragmentación en escala global del proceso productivo y la gran distancia tecnológica que separa las economías de los dos países.

Palabras clave: maquila, manufacturas, crecimiento, fragmentación, productividad.

\begin{abstract}
The maquiladora temporary employment program became permanent, as a strategy to accelerate industrial growth. After three decades of its existence, its effects on productivity, its integration into aggregate national value and the overall growth of the manufacturing sector is not fulfilling what was expected of it. The factors accounting for this result are the operation of stimuli provided by the U.S. and Mexican governments, the economic rationality of fragmentation of the productive process on a global scale and the great technological distance that separates the economies of the two countries.
\end{abstract}

Key words: maquiladora, manufactures, growth, fragmentation, productivity.

\footnotetext{
* Profesora investigadora de la Facultad Latinoamericana de Ciencias Sociales. Correo electrónico: apuyana@flacso.edu.mx

** Profesor investigador de El Colegio de México. Correo electrónico: jromero@colmex.mx
} 


\section{Résumé}

L'industrie de sous-traitance à programme temporel de l'emploi s'est transformée en permanente, comme une stratégie pour accélérer la croissance industrielle. Après trois décades d'existence, ses effets dans la productivité, dans l'intégration de la valeur ajoutée nationale, et dans la croissance de tout le secteur de sous-traitance n'ont pas rempli les attentes. Les facteurs qui expliquent ce résultat sont l'opération des encouragements octroyés par les gouvernements des USA et du Mexique, c'est à dire la rationalité économique de la fragmentation à l'échelle globale du processus productif et la trop grande distance technologique qui sépare les économies des deux pays.

Mots clés: sous-traitance, manufactures, croissance, fragmentation, productivité.

\section{Resumo}

A maquia de programa temporal de emprego tornou-se permanente, como estratégia para acelerar o crescimento industrial. Logo de três décadas de existencia, seus efectos na produtividade, a integração de valor agregado nacional e o crescimento de todo o setor manufatureiro não cumpriram com as expectativas. Os fatores que explicam o resultado são a operação dos estímulos outorgados pelos governos dos Estados Unidos e do México; a racinalidade econômica da fragmentação na escala global do processo produtivo além da grande distância tecnológica que separam as economias dos dois paises.

Palavras chave: maquia, manufaturas, crescimento, fragmentação, produtividade. 


\section{Introducción}

$\mathrm{E}$ xiste una preocupación creciente por los resultados de las reformas económicas implantadas por México durante los años ochenta. A partir de ellas, la economía mexicana perdió el dinamismo que tuvo durante la ineficiente etapa de sustitución de importaciones. El ingreso por habitante, en términos reales, prácticamente no se ha modificado desde 1982, y la brecha entre el ingreso por habitante de México y Estados Unidos, en lugar de disminuir, se amplió de manera continua durante las dos últimas décadas.

Con las reformas iniciadas hace cuatro lustros, se esperaba que la economía mexicana iniciara un proceso de crecimiento rápido y sostenido, y que los niveles de vida de su población se acercaran a los registrados por su principal socio comercial, Estados Unidos. A 10 años de dichas reformas, los resultados no han sido satisfactorios, pese a que la apertura comercial jugó el papel central en ellos.

La justificación de la apertura comercial descansaba en dos argumentos centrales. En primer lugar, permitiría abaratar insumos y bienes de capital importados, con lo cual caerían los costos de producción, aumentaría la competitividad de los productos mexicanos en el extranjero, exportaríamos más y los bienes importables enfrentarían con éxito la competencia en el mercado interno. Se pensaba que desaparecería el fantasma de la escasez de divisas y los frenos en el crecimiento debido a la incapacidad de importar los insumos y los bienes de capital que demandaba el crecimiento. Al exportar más, el crecimiento económico del país quedaría garantizado.

En este sentido, en 1990 una analista señaló lo siguiente: "Si la apertura comercial falla en producir su principal objetivo de reducir la restricción de balanza de pagos, el PRI como partido en el poder se llevará mucho de la culpa" (Weintraub, 1990:157). En diciembre de 1994, cuando la economía mexicana llevaba abierta varios años, sobrevino una crisis de balanza de pagos que provocó la peor recesión económica desde la década de los años treinta. En las elecciones de 2000, el PRI perdió la presidencia de la República. En ese año, el presidente electo Vicente Fox propuso para su primer año de gobierno un programa económico de austeridad, con el fin de contener el crecimiento en el déficit en cuenta corriente (Reforma, 11 de octubre de 2000).

Lo anterior puso de manifiesto que la principal fuente de restricción de la balanza de pagos sobre el crecimiento no es el proteccionismo, sino el manejo inadecuado del tipo de cambio. Al iniciar el siglo xxI, cuando la economía mexicana se encontraba prácticamente abierta, dicho manejo aún provoca problemas de balanza de pagos que limitan su crecimiento.

\section{Desaarrollo}


El segundo argumento se relaciona con el efecto en los salarios y la migración. Los funcionarios de la época señalaban que en la nueva división internacional del trabajo —que haría posible la apertura comercial—, México se especializaría en productos intensivos de mano de obra, la cual ejercería gran presión sobre el mercado de trabajo, al generar empleos, elevar salarios y disminuir la emigración.

De acuerdo con este razonamiento,

la reducción y eliminación de las barreras comerciales dan lugar a una asignación y utilización más eficiente de los recursos productivos. En este contexto, los países pueden concentrar su esfuerzo productivo en generar aquellos bienes para los cuales cuentan con ventajas comparativas, y al hacerlo se supone que ello tendría efectos favorables sobre el empleo y los salarios y, por lo tanto, sobre la reducción de las disparidades económicas entre los países, lo que podría transformar las condiciones que determinan los movimientos migratorios internacionales (Tuirán, Partida y Ávila, 2000:55).

Este trabajo analiza los fundamentos teóricos del segundo argumento: la expectativa de una relación positiva entre especialización y remuneraciones a los factores. Comprobamos que no existe fundamento teórico para esperar una relación así y se propone una explicación para estos resultados inesperados.

A más de dos décadas de la apertura comercial y dos lustros del tLCAN, México es una de las economías más abiertas del mundo, exporta cerca de $30.0 \%$ del PIB y de esta cantidad, $87 \%$ son manufacturas. Entre las exportaciones manufactureras, la mitad proviene de dos versiones de la intensiva en trabajo, la maquila. En efecto, la Gráfica 1 presenta el coeficiente de apertura del PIB —medido como el coeficiente de las exportaciones más las importaciones por el PIB, de México y otras naciones- para ilustrar el avance de la liberalización comercial en nuestro país. Es evidente la mayor apertura de la economía mexicana en comparación con la estadounidense, y el esfuerzo en someter su producción nacional a la competencia externa, expresado por el elevado crecimiento del coeficiente de apertura (3.2\%) durante 1990-2002. Los efectos anunciados de la liberalización deberían ser ya contabilizables.

Sin embargo, los salarios reales en el país no han aumentado - tampoco se han expandido - a la velocidad de las exportaciones manufactureras y maquiladoras, estas últimas sin la participación en la generación del PIB ni del empleo totales. Conviene preguntarse: ¿estos resultados son una aberración de la teoría económica o lo que se nos ofreció carecía de fundamento sólido?

Los antecedentes y fundamentos teóricos que vinculan el crecimiento de las exportaciones con las remuneraciones a los factores, en especial con las exportaciones manufactureras que tienen que ver con la fragmentación de los procesos productivos serán revisados en detalle. En el caso de México, dicha fragmentación comprende, además de la actividad maquiladora, prácticamente la totalidad de las exportaciones manufactureras. 


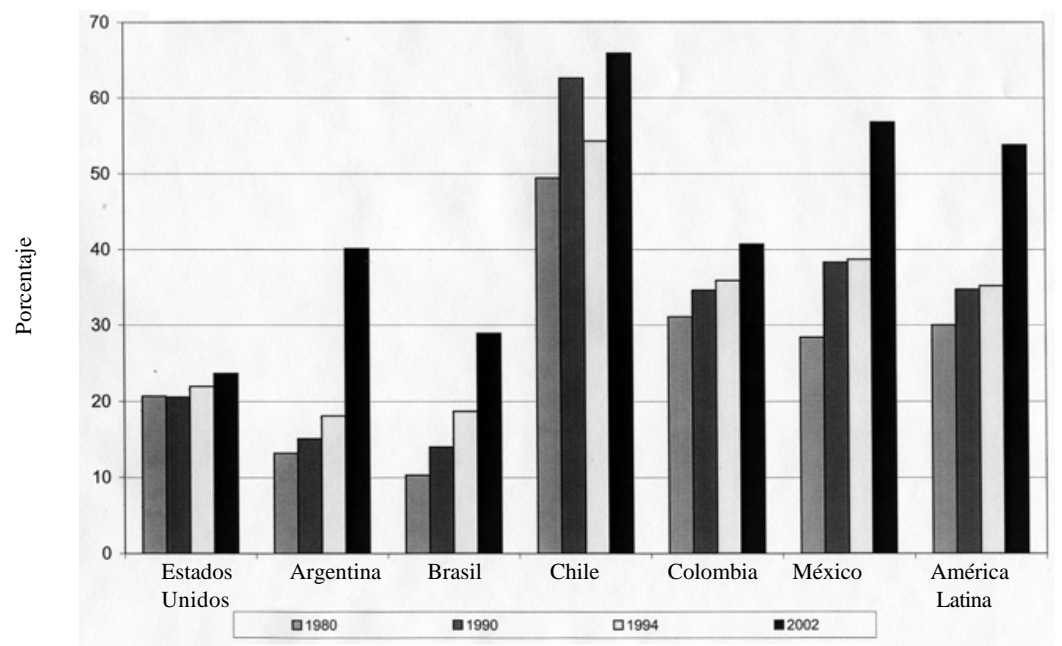

Gráfica 1. Valor y tasas de crecimiento anual promedio del coeficiente de apertura del PIB (México y otros países).

Fuente: Handbook of Statistic, UNCTAD.

\section{Exportaciones}

A partir de 1982, con la administración de Miguel de la Madrid, México abandonó gradualmente la estrategia de sustitución de importaciones adoptada desde 1940 y comenzó a liberalizar su economía. El papel del gobierno se redujo, se vendió la mayoría de las empresas públicas y se desregularon muchos aspectos de la economía, como el transporte y el sector financiero. El proceso también incluyó la apertura del país a los mercados internacionales de capital y la eliminación de la mayor parte de las barreras al comercio. ${ }^{1}$

El resultado de estas medidas, en términos de comercio internacional, ha sido notable. De 1980 a 2000 las exportaciones crecieron a una tasa promedio de $7.9 \%$ al año, dos puntos porcentuales más que en el periodo 1940-1982; esto, a pesar de que el valor de las exportaciones de las actividades extractivas (principalmente petróleo) se redujo considerablemente durante el lapso citado. Este rápido crecimiento se reflejó en el cambio en la composición de las exportaciones e importaciones como porcentaje del PIB (véase Cuadro 1).

\footnotetext{
Entre 1983 y 1984, las autoridades comenzaron a desmantelar el sistema de protección a la indus tria nacional; durante esos dos años, $16.5 \%$ de las importaciones fueron excluidas del requisito de permiso previo y la tasa promedio se redujo 22\%. El 22 de abril de 1985, México firmó el Entendimiento entre Estados Unidos y México sobre subsidios y derechos compensatorios, y el 24 de julio formalizó su entrada al GATT. En ese año, el porcentaje de importaciones que no requerían permiso de importación alcanzó 69.1\%. En 1993 México firmó el Tratado de Libre Comercio de América del Norte y, desde entonces, el país ha establecido otros nueve tratados comerciales, incluyendo uno con la Unión Europea.
} 
ALICIA PUYANA MUTISY JOSÉ ANTONIO ROMERO TELLAECHE

Cuadro 1

Exportaciones e importaciones como porcentaje del PIB

\begin{tabular}{|c|c|c|c|c|c|c|}
\hline Año & $\begin{array}{c}\text { Exportaciones } \\
\text { totales }\end{array}$ & $\begin{array}{l}\text { Exportaciones } \\
\text { maquiladoras }\end{array}$ & $\begin{array}{c}\text { Exportaciones } \\
\text { de las no } \\
\text { maquiladoras }\end{array}$ & $\begin{array}{c}\text { Importaciones } \\
\text { totales }\end{array}$ & $\begin{array}{l}\text { Importaciones } \\
\text { maquiladoras }\end{array}$ & $\begin{array}{c}\text { Importaciones } \\
\text { de las no } \\
\text { maquiladoras }\end{array}$ \\
\hline 1980 & 7.36 & 1.03 & 6.33 & 8.95 & 0.74 & 8.21 \\
\hline 1985 & 18.04 & 3.43 & 14.61 & 11.75 & 2.45 & 9.30 \\
\hline 1990 & 15.50 & 5.30 & 10.20 & 15.80 & 3.90 & 11.90 \\
\hline 1991 & 13.60 & 5.00 & 8.50 & 15.90 & 3.70 & 12.20 \\
\hline 1992 & 12.70 & 5.10 & 7.60 & 17.10 & 3.80 & 13.30 \\
\hline 1993 & 12.90 & 5.40 & 7.50 & 16.30 & 4.10 & 12.20 \\
\hline 1994 & 14.40 & 6.20 & 8.20 & 18.70 & 4.80 & 13.90 \\
\hline 1995 & 26.80 & 10.50 & 16.30 & 24.30 & 8.80 & 15.50 \\
\hline 1996 & 28.90 & 11.10 & 17.80 & 26.90 & 9.20 & 17.70 \\
\hline 1997 & 27.50 & 11.30 & 16.30 & 27.44 & 9.10 & 18.34 \\
\hline 1998 & 27.90 & 12.60 & 15.30 & 29.70 & 10.10 & 19.60 \\
\hline 1999 & 28.20 & 13.20 & 15.00 & 29.40 & 10.40 & 19.00 \\
\hline 2000 & 28.20 & 13.00 & 15.20 & 29.20 & 10.20 & 19.00 \\
\hline
\end{tabular}

Fuente: Presidencia de la República, Informe de Gobierno, varios años.

Las exportaciones de manufacturas registraron el mayor crecimiento. Durante el periodo 1982-2000 crecieron a una tasa anual de 18.8\%, 11 puntos porcentuales más que en el periodo 1940-1982. Las exportaciones agrícolas aumentaron a una tasa anual de 6.2\%, casi cuatro puntos porcentuales más que en el periodo 1940-1982. Estas diferentes tasas de crecimiento de las categorías de exportaciones trajeron consigo un cambio notable en la composición de las exportaciones. En el Cuadro 2 observamos que las exportaciones mineras en 1982 (básicamente petróleo crudo) representaban 76\% de las totales. Para el año 2000 este porcentaje se redujo a $9 \%$; en contraste, las exportaciones manufactureras pasaron de $16 \%$ del total en 1982 a $87 \%$ en 2000 .

El crecimiento espectacular de las exportaciones en años recientes pareciera indicar el éxito de las reformas económicas. Esto, sin embargo, no ha sido así. La expansión de las exportaciones no se ha transmitido al resto de la economía. En la Gráfica 2 presentamos, en un diagrama de dispersión, la relación entre las tasas de crecimiento de las exportacio-

Cuadro 2

Composición de las exportaciones (porcentaje)

\begin{tabular}{lrrrrrrrrr}
\hline & 1980 & 1985 & 1990 & 1995 & 1996 & 1997 & 1998 & 1999 & 2000 \\
\hline Agricultura & 9.9 & 6.5 & 8.1 & 5.1 & 4.2 & 3.5 & 3.2 & 4.3 & 3.0 \\
Manufactura & 23.0 & 29.7 & 56.0 & 84.9 & 94.4 & 86.7 & 90.9 & 90.1 & 87.0 \\
Minería y petróleo & 64.2 & 63.8 & 35.8 & 10.1 & 13.0 & 9.9 & 5.9 & 5.5 & 9.0 \\
\hline
\end{tabular}

Fuentes: NAFISA, La economía mexicana en cifras, 1990; Presidencia de la República, Informe de Gobierno, varios años. 


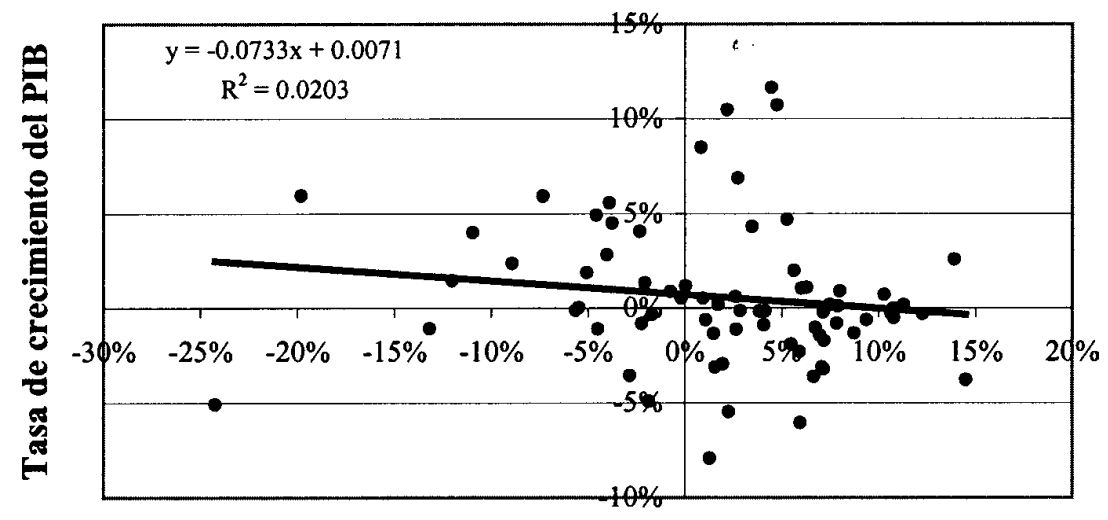

Tasa de crecimiento de las exportaciones

Gráfica 2. Relación entre tasas de crecimiento de las exportaciones y tasas de crecimiento del PIB (datos trimestrales, 1983-2000).

Fuente: Banco de México.

nes y del PIB durante el periodo 1983-2000. Como se muestra, la relación es negativa pero no significativa, lo cual indica, al menos, que no hubo relación entre el crecimiento de las exportaciones y el nivel general de actividad económica. ${ }^{2}$

De 1982 — año en que irrumpió la crisis de deuda y se rivirtió la estrategia de sustitución de importaciones- a 2000, el PIB por habitante en México se ha incrementado a una tasa anual de $0.1 \%$. Durante el mismo periodo, en Estados Unidos el ingreso por habitante creció a una tasa de $2.9 \%$ al año. Esta diferencia en las tasas de crecimiento ha hecho más grande la brecha entre el ingreso por habitante en los dos países; en 2000, el PIB por habitante en Estados Unidos era seis veces mayor que el de México, cifra superior a la registrada en 1960 (véase Cuadro 3). ${ }^{3}$ Se considera al valor promedio del ingreso per capita (PIB/C) un buen indicador del nivel de desarrollo y una aproximación a la dotación de factores. Según Helpman y Krugman (1981), los países con ingresos per capita superiores tienen mayor capacidad para innvoar y producir bienes diferenciados, con procesos intensivos en capital y tecnología; además, al tener más información y superiores sistemas de comunicación, expanden aceleradamente su comercio en bienes diferenciados (Loertscher y Wolter, 1980). El ingreso per capita señala la estructura de la demanda y, en virtud de la

2 En estudios empíricos de este tipo es común usar la prueba de causalidad de Granger (1969) para determinar si existe relación entre las exportaciones y el crecimiento económico. Un estudio de este tipo fue realizado para México por Cuadros (2000), en el cual la autora destaca: "la ausencia de causalidad entre las diferentes categorías de exportaciones consideradas y la tasa neta de crecimiento del producto para el periodo 1983 1997". Otras investigaciones para diferentes países encuentran resultados similares: Jung y Marshall (1985) y Chow (1987).

3 Para un estudio reciente sobre la convergencia entre los países integrantes del TLCAN, véase Puyana y Romero (2005a).

\section{Desaarrollo}




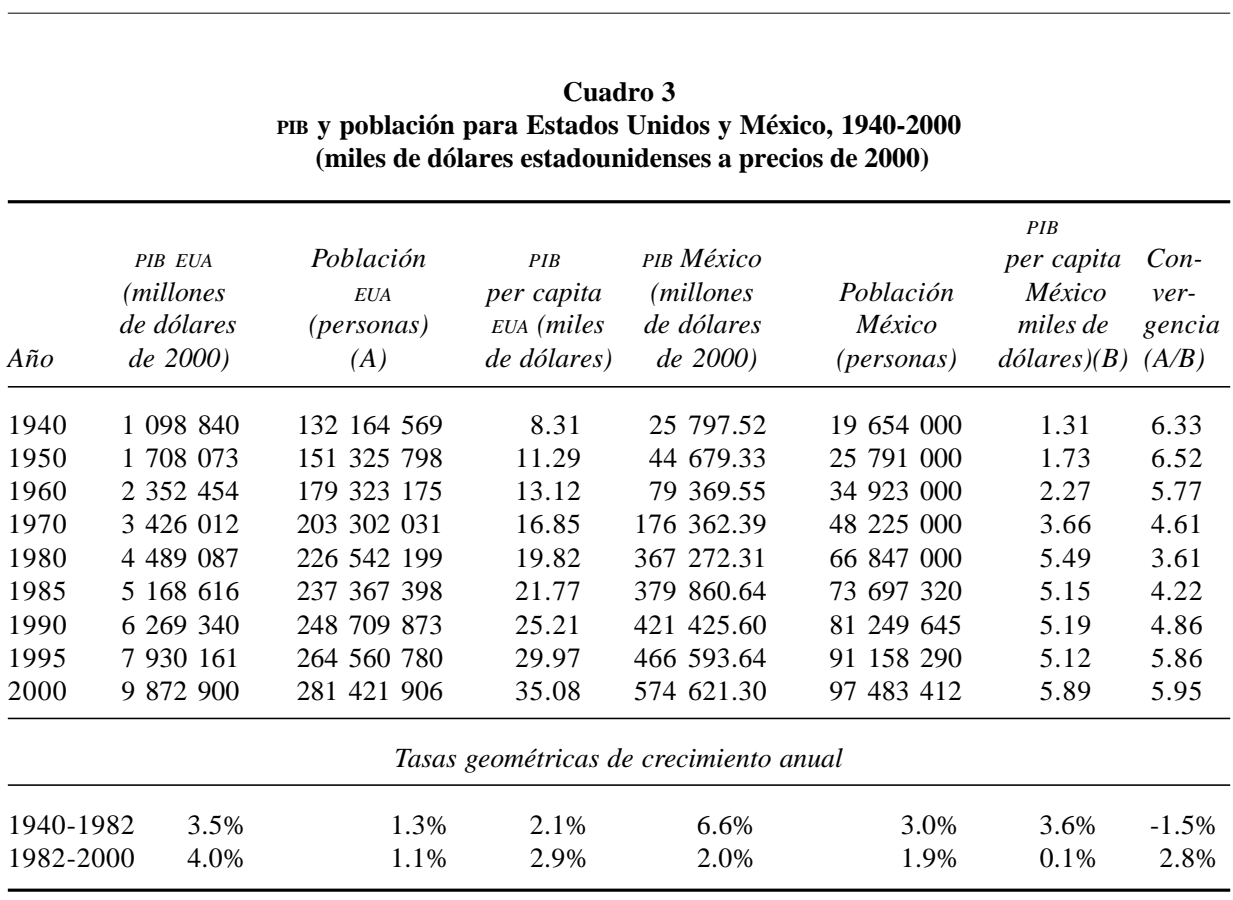

Fuente: INEGI, Estadísticas históricas de México, 1985; NAFINSA, La economía mexicana en cifras, 1990; Presidencia de la República, Informe de Gobierno, varios años.

diferenciación de su oferta, la capacidad de la producción de un país para adaptarse a los cambios en el ambiente internacional con mayor flexibilidad que las naciones menos desarrolladas. De acuerdo con el historiador John Coatsworth, el ingreso por habitante es el indicador que mejor revela al economista y al historiador el nivel de productividad y, por lo tanto, el estado de una economía (Coatsworth, 1990:25).

Tomando en cuenta que el crecimiento del PIB/C es un indicador del crecimiento de la productividad, se puede asumir que se amplía la brecha en tanto se incrementan las distancias en la productividad. Esto tiene implicaciones significativas en términos de los efectos del comercio y la migración, entre otras. De acuerdo con Linder, el comercio internacional no se realiza en las líneas ricardianas (entre países desiguales en productividad y dotación de factores, es decir, intersectorialmente, en una dirección norte-sur); se realiza en dirección norte-norte, entre naciones similares, en dotación factorial y en nivel de productividad, con similar ingreso per capita y grado de diversificación de producción y demanda. Además, es mayo-ritario un intercambio interindustrial, cuyo segmento más dinámico es el de manufacturas con alto nivel de tecnología. Si los países latinoamericanos se distancian en productividad respecto de sus socios comerciales, corren el riesgo de ser desplazados de sus mercados. En presencia de la fragmentación de los procesos productivos en escala global, el riesgo es doble: pueden ser desplazados de la producción y las exportaciones de los segmentos más intensivos en tecnología por los países más avanzados 
Cuadro 4

México: PIB por sector, 1940-2000

(millones de pesos de 1993)

\begin{tabular}{|c|c|c|c|c|c|c|c|c|c|}
\hline Año & PIB total ${ }^{1}$ & Agricultura & Minería & $\begin{array}{l}\text { Manu- } \\
\text { factura }\end{array}$ & $\begin{array}{l}\text { Cons- } \\
\text { trucción }\end{array}$ & $\begin{array}{c}\text { Elec- } \\
\text { tricidad }\end{array}$ & Comercio & Transporte & $\begin{array}{c}\text { Otros } \\
\text { servicios }\end{array}$ \\
\hline 1940 & 78206.0 & 15169.6 & 5006.3 & 12047.5 & 1958.0 & 592.9 & 24183.9 & 1988.1 & 17259.8 \\
\hline 1950 & 137411.1 & 26339.4 & 6937.9 & 23495.7 & 4994.7 & 1021.0 & 39590.0 & 4468.5 & 30563.8 \\
\hline 1960 & 250457.6 & 31564.8 & 3011.3 & 39971.5 & 11873.5 & 1199.5 & 56310.6 & 16063.5 & 91693.6 \\
\hline 1970 & 472024.1 & 43350.1 & 5026.3 & 87520.8 & 26405.5 & 4258.8 & 112886.1 & 29249.1 & 174862.3 \\
\hline 1980 & 891084.7 & 60475.7 & 12452.9 & 169895.0 & 52046.4 & 10421.2 & 211761.8 & 81217.5 & 312632.8 \\
\hline 1985 & 961718.1 & 70138.2 & 15211.5 & 178412.3 & 48275.5 & 14110.1 & 210345.5 & 86436.8 & 361356.8 \\
\hline 1990 & 1049063.9 & 69603.9 & 15602.5 & 205524.5 & 48040.1 & 17270.3 & 225058.2 & 94872.6 & 399505.6 \\
\hline 1995 & 1131752.8 & 74168.2 & 16223.0 & 217581.7 & 45958.4 & 19613.8 & 226959.9 & 111081.2 & 453582.2 \\
\hline 2000 & 1479497.2 & 82758.4 & 19173.5 & 317482.1 & 63343.1 & 25187.4 & 319592.1 & 170913.6 & 439409.2 \\
\hline \multicolumn{10}{|c|}{ Tasas geométricas de crecimiento anual } \\
\hline $1940-1$ & $5.97 \%$ & $3.41 \%$ & $2.68 \%$ & $6.39 \%$ & $7.95 \%$ & $7.17 \%$ & $5.32 \%$ & $8.93 \%$ & $7.14 \%$ \\
\hline $1982-2$ & $2.41 \%$ & $1.46 \%$ & $1.20 \%$ & $3.28 \%$ & $0.76 \%$ & $4.10 \%$ & $1.92 \%$ & $3.90 \%$ & $1.31 \%$ \\
\hline
\end{tabular}

${ }^{1}$ El PIB total difiere de la suma del de los sectores por "Servicios Bancarios Imputados".

Fuentes: NAFINSA, La economía mexicana en cifras, 1978; INEGI, Estadísticas históricas de México, 1999; Presidencia de la República, Informe de Gobierno, varios años.

y ceder los de mayor intensidad de mano de obra a los que disponen de abundante oferta de trabajo (Arndt y Kierzkowski, 2001). México es un ejemplo claro de este proceso (Puyana y Romero, 2005b).

De ahí la conveniencia de emplear el nivel del producto interno bruto per capita (PIB/C) y su evolución durante periodos pre y posreformas para analizar el crecimiento de la productividad de las economías, los factores que explican su crecimiento y la convergencia o ausencia de ella con los niveles de desarrollo y productividad de los países desarrollados.

La comparación de las tasas de crecimiento por actividad económica entre 1940-1982 y 1982-2000 muestra resultados muy desfavorables para el periodo reciente. Entre 1982 y 2000, en la mayor parte de los casos, las tasas de crecimiento del valor agregado en estas actividades se redujeron a menos de la mitad de las registradas en el periodo previo. Un caso notable son las manufacturas, que en años recientes experimentaron un aumento espectacular de las tasas de crecimiento de exportaciones y, pese a ello, el sector muestra tasas de casi la mitad de las registradas en el lapso de sustitución de importaciones (véase Cuadro 4).

La creciente especialización de México en actividades fragmentadas ha producido pocas repercusiones en el resto de la economía. Como se muestra en la Gráfica 3, la participación de las maquiladoras en el total de exportaciones se incrementó de 14\% en 1980 a $46 \%$ en 2000. Esto significa que el país se está especializando en actividades de maquila. ${ }^{4}$

$4 \quad$ Es más, con el TLCAN se ha reducido el atractivo de las actividades de maquila y muchas de las empresas exportadoras se comportan como maquiladoras sin la necesidad de entrar en este programa.

\section{DeSarrollo}




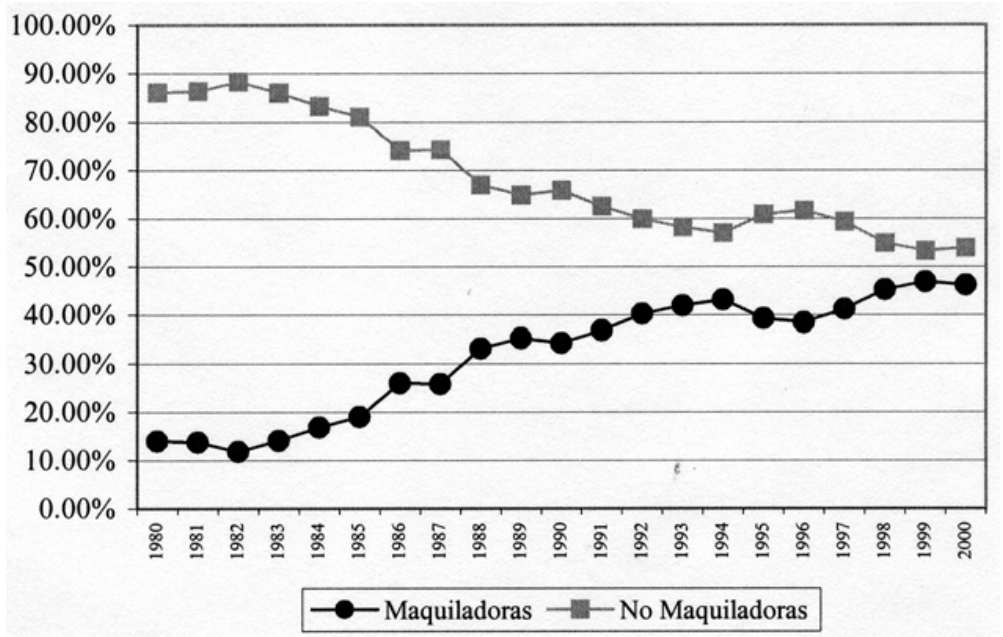

Gráfica 3. Composición de las exportaciones.

Fuente: Presidencia de la República, Informe de Gobierno, varios años.

La creciente especialización de México en actividades fragmentadas explica el bajo impacto económico de las exportaciones en el PIB.

Cuando analizamos la nacionalidad de las firmas que realizan el mayor porcentaje de las exportaciones, encontramos que la mayor parte de éstas son extranjeras. En el Cuadro 5 mostramos que las firmas con inversión extranjera directa (IED) realizan alrededor de $60 \%$ del total de las exportaciones no petroleras. En el sector manufacturero esta participación es todavía más alta.

\section{Comportamiento de las remuneraciones a los factores}

De 1980 a 2000, la remuneración promedio a los trabajadores registró ciertos altibajos coyunturales que no modificaron la tendencia general al estancamiento. Como se muestra en la Gráfica 4 -que utiliza datos de 73 ramas de la clasificación industrial internacional unificada (CIIU) a dos dígitos de desagregación, para el periodo 1980-2000—, la trayectoria del valor medio de las remuneraciones es prácticamente 0 (y estadísticamente no significativa). Es decir, durante el lapso analizado no se establece ninguna tendencia definida. Los salarios reales se deterioraron durante los periodos de ajuste estructural (1980-1988), y estabilización macroeconómica (1983-1988), y se recuperaron durante el periodo 19882000, aunque no lo suficiente para restablecer el nivel del salario real de 1981.

Una vez que el contenido regional se satisface, la diferencia entre exportaciones regulares y exportaciones de maquila desaparecen. Por lo tanto, la importancia de este tipo de empresas es mayor de lo que sugiere la Gráfica 3. 
Cuadro 5

Participación de las compañías con IED en las exportaciones no petroleras (porcentajes)

\begin{tabular}{lrrrrrrrr}
\hline & 1993 & 1994 & 1995 & 1996 & 1997 & 1998 & 1999 & 2000 \\
\hline No petroleras & 58.0 & 62.2 & 62.2 & 65.6 & 65.2 & 64.5 & 61.0 & 61.3 \\
Agricultura & 4.5 & 8.2 & 11.0 & 15.0 & 17.8 & 15.0 & 14.4 & 15.2 \\
Minería & 44.8 & 31.4 & 40.4 & 47.8 & 45.0 & 39.6 & 39.9 & 36.0 \\
Manufacturas & 62.6 & 66.3 & 66.4 & 68.7 & 67.9 & 66.8 & 63.1 & 63.3 \\
Maquiladoras & 69.0 & 72.5 & 73.7 & 73.4 & 71.6 & 69.9 & 66.2 & 60.9 \\
No maquiladoras & 55.5 & 59.5 & 60.0 & 64.7 & 64.5 & 63.8 & 59.7 & 66.3 \\
\hline
\end{tabular}

Fuente: Banco de México.

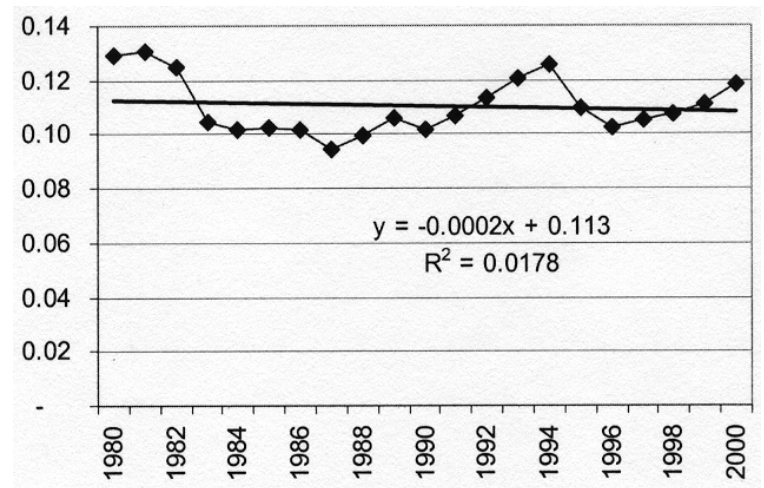

Gráfica 4. Evolución de las remuneraciones reales al trabajo* (miles de pesos de 1980).

* Mediana del total de pagos al trabajo entre el número de trabajadores, deflactados por el índice de precios al consumidor.

Fuente: INEGI, Sistema de cuentas nacionales, México, 2000.

Las fluctuaciones de los salarios reales durante el periodo 1980-2000 están íntimamente relacionadas con la evolución del tipo de cambio real. ${ }^{5}$ Durante 1980 y 1982 el peso se sobrevaluó y elevó el salario real. La crisis de la deuda en 1982 puso fin abrupto a esta ganancia real de los salarios. De 1982 a 1988 la moneda nacional se subvaluó, con lo cual se redujo el salario real ${ }^{6}$ y se elevaron los precios —en moneda local — de los bienes importados, otorgando protección a la producción de bienes transables y estimulando el empleo. La subvaluación del peso se mantuvo hasta 1988, cuando se establecieron los

5 La relación entre salarios reales y tipo de cambio real radica en la inclusión de bienes importados en la canasta de consumo empleada como base de cálculo del índice de precios al consumidor. Al incluir en dicha canasta los precios de los bienes importados, la subvaluación o sobrevaluación del peso reduce o eleva el salario real compatible con cierto valor de la productividad del trabajo medida a precios del productor.

6 Durante esos años se utilizó la subvaluación del peso y el control salarial como medidas antiinflacio narias y para lograr el superávit comercial necesario para financiar el servicio de la deuda externa, en ausencia de otra forma de financiamiento.

\section{Desaarrollo}


pactos. A partir de entonces, la política económica cambió y privilegió la sobrevaluación cambiaria: al estimular la elevación del salario real, las importaciones fungieron como mecanismo estabilizador de los precios, pero con menor producción nacional. Los resultados son obvios: desestímulo a la producción de bienes transables (especialmente los intensivos en mano de obra y otros insumos nacionales), informalidad, desempleo y aumento del contenido importado en el PIB. Esta política terminó dramáticamente con la crisis cambiaria de 1994. La respuesta a esta última fue la devaluación real del peso durante 1995-1996 y la caída del salario real. Una vez más, a partir de 1997 y hasta 2000 (pero también hasta 2003), las autoridades monetarias y cambiarias optaron por la sobrevaluación del peso con todas sus consecuencias, una de las cuales es la elevación del salario real y la acumulación del desempleo abierto o encubierto.

Con este recuento se enfatiza que, durante las dos décadas en análisis, los salarios medios permanecieron estáticos y que sus fluctuaciones están ligadas, en buena medida, a los cambios de rumbo en una política cambiaria, que parece preferir la sobrevaluación del peso como mecanismo antiinflacionario, a la búsqueda de una tasa real de cambio que favorezca el empleo.

Con otras fuentes, y para diferentes años, analizamos este fenómeno y encontramos resultados similares. El Cuadro 6, basado en datos anuales de ocho encuestas de empleo (Encuesta Nacional de Empleo para los años 1991, 1993 y de 1995 al 2000), muestra la evolución de los salarios por tipo de trabajo. Para cada encuesta se ilustran los salarios promedio de seis tipos de trabajo y la respectiva tasa de crecimiento salarial. Son evidentes: el decremento en salario promedio anual de los menos y de los más educados; crecimiento modesto de los niveles intermedios y crecimiento moderado en los salarios promedio del conjunto de los trabajadores (véase columna G, tasas de crecimiento).

La misma tendencia aparece cuando se divide el trabajo en dos categorías: no calificado (de cero a doce años de educación formal: $\mathrm{L} 0+\mathrm{L} 1+\mathrm{L} 2+\mathrm{L} 3$ ) y calificado (con uno o más años de educación universitaria, incluyendo posgrados: L4+L5) (véase Cuadro 7). El salario promedio de todos los trabajadores creció a una tasa promedio de $0.9 \%$ entre 1991 y 2000, el de los no calificados $0.03 \%$, en tanto que el de los calificados decreció $-1.14 \%$. Esto quiere decir que de 1991 a 2000 la distancia entre los salarios de los calificados en relación con los no calificados se redujo de 3.76 veces en 1991 a 3.62 en 2000.

En contraste con la tendencia al estancamiento de los salarios reales en los últimos veinte años, las remuneraciones al capital muestran una tendencia a la alza (estadísticamente significativa) durante este periodo (véase Gráfica 5).

7 Esta diferencia en las tasas de crecimiento de los salarios implicó una menor desigualdad entre ambos tipos de trabajo, lo cual puede observarse en el renglón Razón, que registra el cociente del salario medio de los calificados y los no calificados. 
Cuadro 6

Salario promedio real por tipo de trabajo (miles de pesos de 1990)

\begin{tabular}{crrrrrrrrr}
\hline $\begin{array}{l}\text { Tipo de } \\
\text { trabajo }\end{array}$ & 1991 & 1993 & 1995 & 1996 & 1997 & 1998 & 1999 & 2000 & $G$ \\
\hline L0 & 8.51 & 6.98 & 6.95 & 7.37 & 7.70 & 7.58 & 9.23 & 7.98 & $-0.72 \%$ \\
L1 & 11.35 & 12.06 & 10.86 & 10.78 & 10.93 & 11.01 & 11.46 & 12.20 & $0.80 \%$ \\
L2 & 33.44 & 42.60 & 33.61 & 30.75 & 29.85 & 31.27 & 33.15 & 34.80 & $0.44 \%$ \\
L3 & 42.25 & 51.88 & 47.43 & 38.51 & 41.19 & 41.32 & 43.64 & 44.64 & $0.61 \%$ \\
L4 & 72.65 & 82.64 & 69.37 & 61.58 & 68.49 & 64.89 & 68.49 & 73.56 & $0.14 \%$ \\
L5 & 80.59 & 90.03 & 75.96 & 71.93 & 81.80 & 77.97 & 92.46 & 80.41 & $-0.02 \%$ \\
\hline Total & 16.01 & 18.48 & 16.61 & 15.86 & 16.62 & 16.75 & 17.65 & 18.97 & $1.88 \%$ \\
\hline
\end{tabular}

G: tasa geométrica de crecimiento: 1991-2000.

L0: sin escolaridad. L1: de uno a seis años de escolaridad (primaria). L2: de siete hasta nueve años de escolaridad (secundaria) + técnica I (primaria requerida), terminada o no. L3: de diez hasta doce años de escolaridad (preparatoria) + técnica II (secundaria requerida), terminada o no. L4: uno o mas años de estudios universitarios + técnica III (preparatoria requerida), terminada o no. L5: uno o más años de posgrado, maestría, doctorado.

Fuente: Secretaría del Trabajo y Previsión Social, Encuesta Nacional de Empleo, varios años.

Cuadro 7

Promedio de remuneraciones a trabajadores no calificados, calificados y del conjunto de trabajadores ( 73 ramas)

(miles de pesos de 1990)

\begin{tabular}{|c|c|c|c|c|c|c|c|c|c|}
\hline & 1991 & 1993 & 1995 & 1996 & 1997 & 1998 & 1999 & 2000 & $G$ \\
\hline \multicolumn{10}{|c|}{ No calificado (a) } \\
\hline Promedio & 12.04 & 13.69 & 12.01 & 11.27 & 12.11 & 11.93 & 12.51 & 13.05 & $0.03 \%$ \\
\hline \multicolumn{10}{|c|}{ Calificado (b) } \\
\hline Promedio & 45.32 & 57.88 & 50.97 & 42.68 & 43.34 & 41.11 & 48.82 & 47.21 & $-1.14 \%$ \\
\hline \multicolumn{10}{|c|}{ Razón (b/a) } \\
\hline & 3.76 & 4.23 & 4.24 & 3.79 & 3.58 & 3.45 & 3.9 & 3.62 & $-1.16 \%$ \\
\hline \multicolumn{10}{|c|}{ Todos } \\
\hline Promedio & 16.01 & 18.48 & 16.61 & 15.86 & 16.62 & 16.75 & 17.65 & 18.97 & $0.87 \%$ \\
\hline
\end{tabular}

G: tasa promedio de crecimiento.

Razón: salarios promedio de los trabajadores calificados entre el salario promedio de los no calificados.

Fuente: Secretaría del Trabajo y Previsión Social, Encuesta Nacional de Empleo, varios años. 


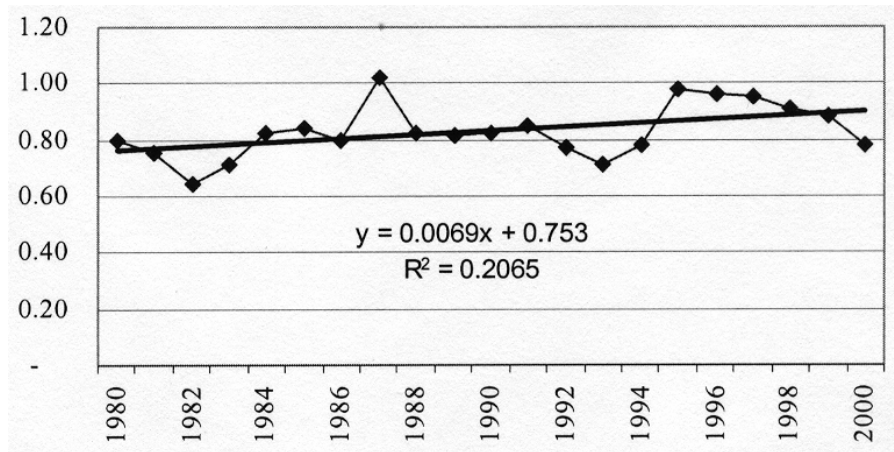

Gráfica 5. Evolución de las remuneraciones reales al capital* (miles de pesos de 1980).

* Mediana de excedente bruto de explotación entre el acervo de capital, deflactado por el índice de precios al consumidor.

Fuentes: INEGi, Sistema de Cuentas Nacionales, México, 2000; Banco de México, Encuesta de acervos, depreciación y formación de capital del Banco de México, 1980-1995, así como estimaciones propias (Puyana y Romero, 2004).

En las páginas que siguen se investigará en qué medida existen elementos teóricos para esperar que el papel de México en la nueva división internacional del trabajo puede llevarnos a una elevación de salarios y a una convergencia en las remuneraciones a los factores con respecto de nuestros principales socios comerciales. Dicho papel se caracteriza por los segmentos intensivos en mano de obra de procesos productivos de bienes — que en forma global son intensivos en tecnología y capital, como son los sectores automotriz, eléctrico y electrónico.

El análisis se basa en el modelo estándar de comercio internacional y la teoría de la fragmentación.

\section{Fragmentación del proceso productivo ${ }^{8}$}

Gran parte de la teoría del comercio internacional se desarrolló a partir del concepto de comercio en bienes finales. Aun la literatura del comercio intraindustria, que por su naturaleza debía considerar al comercio de partes y componentes, se enfocó en el intercambio de variedades de bienes finales.

Aunque el comercio en partes y componentes es muy antiguo, en las últimas décadas su participación en el comercio mundial ha crecido espectacularmente. Pero a pesar de los cambios que éste desarrolla, todavía se valora la ventaja comparativa en términos de productos finales, y la especialización internacional en función de industrias completas y productos integrados.

Los últimos años han sido testigos de la emergencia del comercio intraproducto como forma importante de comercio intraindustria. La especialización intraproducto sólo puede

8 Esta sección se basa en el trabajo de Arndt y Kierzkowski (2001).

\section{Desarrortollo}


darse cuando las fases del proceso productivo pueden separarse físicamente, es decir, en el momento en el cual la manufactura del producto es susceptible de fragmentación.

Durante las últimas dos décadas, el proceso de fragmentación ha adquirido una dimensión internacional y un alto grado de complejidad, ambas constituyen una parte central del fenómeno de globalización.

Los procesos de producción que admiten la fragmentación implican división del trabajo más fina y compleja que aquellos que no la admiten. Con dicha fragmentación, las diferentes fases del proceso productivo pueden separarse espacialmente y llevarse a cabo en sitios distintos, donde los costos de cada fase sean los más bajos. La dispersión espacial de la producción permite producir los componentes en aquellos sitios donde la intensidad de factores sea la más apropiada, en vez de que la intensidad de factores promedio del producto final determine el lugar de la producción. La división internacional del trabajo se basa en la distribución de la producción de los componentes de acuerdo con la intensidad relativa de factores que cada producto requiera y cada país posea.

La coordinación y servicios relacionados con la producción fragmentada son provistos por los llamados lazos de servicios. Éstos están compuestos de actividades tales como transporte, seguros, telecomunicaciones, control de calidad y coordinación, que aseguran que los bloques de producción interactúen en la forma adecuada. La velocidad y eficiencia de los servicios de enlace influye en el grado óptimo de fragmentación.

En años recientes, las innovaciones tecnológicas, la liberalización comercial en servicios, la convergencia en los sistemas legales y de regulación, y una creciente libertad para iniciar operaciones han reducido de manera significativa los costos de los lazos de servicio, lo cual abre nuevas oportunidades para la fragmentación internacional. En la medida en que estos costos se abarataron, se abrieron nuevas opciones y la producción de muchos bienes finales se ha convertido literalmente en un proceso global.

Para analizar la fragmentación conviene plantearse algunas preguntas acerca de distribución factorial del ingreso: ¿quién se beneficia y quién se perjudica cuando la producción de componentes cambia de país?, ¿compartir la producción con un país de bajos salarios afecta al empleo y deprime los salarios en la nación desarrollada y los eleva en el país en desarrollo?, ¿la fragmentación lleva a la convergencia de las remuneraciones a los factores? Para contestar estas preguntas, en las secciones siguientes utilizaremos una versión simple del modelo estándar de comercio internacional.

\section{Fragmentación y remuneraciones a los factores ${ }^{9}$}

El término fragmentación se refiere a la separación de procesos de producción previamente integrados en dos o más componentes o fragmentos. En esta sección exploramos su

9 Esta sección está basada en Arndt y Kierzkowski (2001) y Deardoff (2001). 
efecto en los precios de los factores, según el modelo Heckscher-Ohlin de 2x2x2, con los supuestos usuales. Como veremos, la fragmentación no necesariamente lleva al acercamiento de los precios de los factores entre países.

Considérense dos naciones o grupos de países con diferentes precios de los factores en condiciones de libre comercio, o sea, bajo una situación en la cual no se da la igualación de precios de los factores. Las líneas de isocosto para cada país se muestran en la Gráfica 6 como las líneas $A C D$ para el país abundante en mano de obra (con pendiente $\left.-(w / r)^{S}\right)$, que podemos llamar el sur y $B C E$ para la nación abundante en capital (con pendiente $\left.-(w / r)^{N}\right)$, que llamamos el norte.

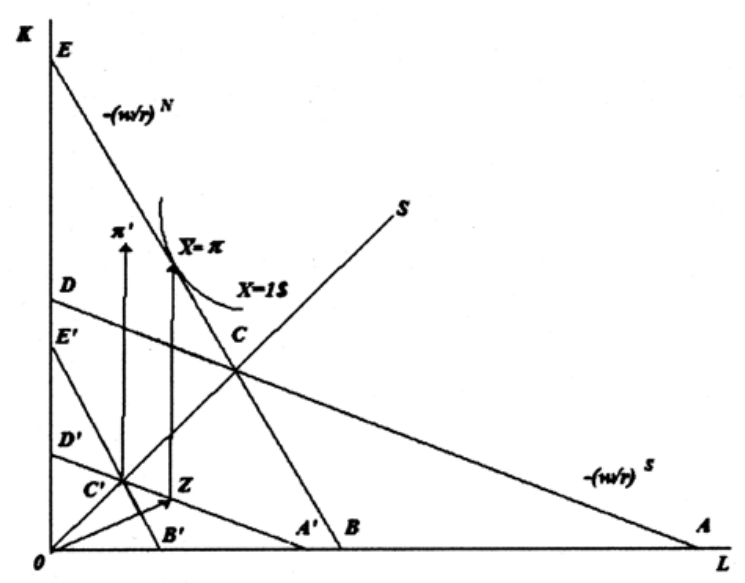

Gráfica 6.

Con el libre comercio podemos identificar qué país va a producir cada bien final. Esto se logra buscando las isocuantas de valor unitario de cada bien (con valor de $1 \$$, no mostradas), las cuales son tangentes a la línea quebrada formada por la parte externa de los dos segmentos de isocosto correspondientes a cada nación (la línea $A C E$ ). Aquí encontramos que todos los bienes que produce el sur son más intensivos en trabajo que todos los del norte. Puesto que existen muchos bienes, algunos de ellos pueden ser elaborados en los dos países, pero para facilitar el análisis consideramos que cada bien se produce en un sola nación. Uno de éstos es $X$, cuya isocuanta de valor unitario se muestra en la Gráfica 6. Ese bien es producido en el norte, ya que es intensivo en capital.

Lo que haremos es suponer que el cambio tecnológico permite fragmentar el proceso integrado y usar por lo menos los mismos recursos que antes de la separación, ${ }^{10}$ es decir, es

10 Si la fragmentación de la tecnología usara menor cantidad de factores que la original, entonces necesariamente ya habría sido utilizada al producirse ambos bloques en un mismo país. Tal posibilidad sería, en realidad, una mezcla de avance tecnológico y fragmentación que no tiene mucho sentido, por lo cual no la exploramos. 
por lo menos igual de costosa (o no costosa) y en general más costosa en términos de factores utilizados que el proceso integrado. Analizaremos ambos casos.

Comenzamos analizando la fragmentación no costosa. Supongamos que en la Gráfica 6 la misma cantidad del bien $X$ que la representada por la isocuanta $X=1 \$$ puede producirse separando en dos bloques el proceso: un fragmento que requiere del vector de factores mostrado por $O Z$ y otro que requiere el vector de factores $Z \pi$.

Estos vectores están dibujados de manera que suman exactamente la misma cantidad de factores que el vector $0=0 \pi$ (no dibujado), el cual representa el total de factores que utiliza el proceso integrado en el norte. Así, los productores en el norte pueden cambiarse a la tecnología fragmentada produciendo todo en su país, sin que les haga daño, pero sin que les beneficie.

Sin embargo, nótese que de los fragmentos dibujados, uno de ellos, $O Z$, no se hubiera producido en el norte de ser un bien final, puesto que su relación capital-trabajo está por abajo de la intersección de las dos líneas de isocosto en $C$. Por lo tanto, como resultado de la separación, surge la posibilidad de que este fragmento se produzca en el sur y no en el norte.

Si no existen impedimentos para ello, este bloque se producirá en el sur y los costos caerán como resultado de la fragmentación internacional, como puede verificarse con el resto de la construcción de la Gráfica 6. Primero dibujamos un nuevo par de curvas de isocosto $A^{\prime} C^{\prime} D^{\prime}$ y $B^{\prime} C^{\prime} E$ ', paralelas a $A C D$ y $B C E$, respectivamente, pero contraídas hacia el origen en la misma proporción, de manera que la envolvente más lejana al origen del nuevo par de líneas toquen el punto más lejano de la flecha $O Z$. Puesto que la línea original mostraba todas las combinaciones de factores en los dos países que valían $1 \$$, el nuevo par de líneas muestra las que valen un poco menos, esto es, las que valen lo mismo que el fragmento $O Z$ en el sur. Puesto que $A^{\prime} C^{\prime} D^{\prime}$ es una línea de isocosto, todos los puntos en ésta tienen el mismo costo en el sur, incluyendo el punto $C$ ' que representa el de producir $O Z$ en el norte y en el sur. Si ahora le añadimos el fragmento $Z \pi a O C$ ', encontramos el costo del conjunto de factores de la tecnología fragmentada, a precios del norte, de la que parte es producida en el sur. Es decir, dibujemos un vector $C^{\prime} \pi$ ' igual en tamaño y dirección a $Z \pi$ a partir del punto $C$ '. La punta de esta flecha en $\pi$ ' muestra el costo a precios del norte del conjunto de factores utilizado por la tecnología total fragmentada, cuando el segmento más intensivo en trabajo es producido en el sur, donde el precio relativo del trabajo es menor.

El hecho de que el punto $\pi$ ' esté por debajo de la línea de isocosto $B C E$ nos dice que el uso de la tecnología fragmentada, aun cuando no es menos costosa en términos de factores utilizados (pues usa exactamente la misma cantidad de factores que el proceso integrado), reduce los costos monetarios si los fragmentos son producidos en diferentes países con precios de factores diferentes. La Gráfica 6 también muestra la reducción de costos monetarios, la cual se mide por la distancia de $\pi$ ' por debajo de $B C E$.

\section{Desaarrollo}


En contraste, la fragmentación costosa se da cuando la nueva tecnología usa más factores que el proceso integrado. Tal caso se muestra en la Gráfica 7, en la cual la tecnología fragmentada se muestra nuevamente por los vectores $O Z$ y $Z \pi$. Esta vez, sin embargo, la suma de factores usados en el proceso fragmentado $O \pi$ es mayor que el utilizado en el proceso integrado 0 (no dibujado).

Si la fragmentación es costosa puede que no se le use, aun cuando uno de los segmentos sea más barato en uno de los países. Lo importante es el ahorro en el costo monetario que resulta al explotar las diferencias en los precios de los factores, comparado con los factores adicionales utilizados por la fragmentación.

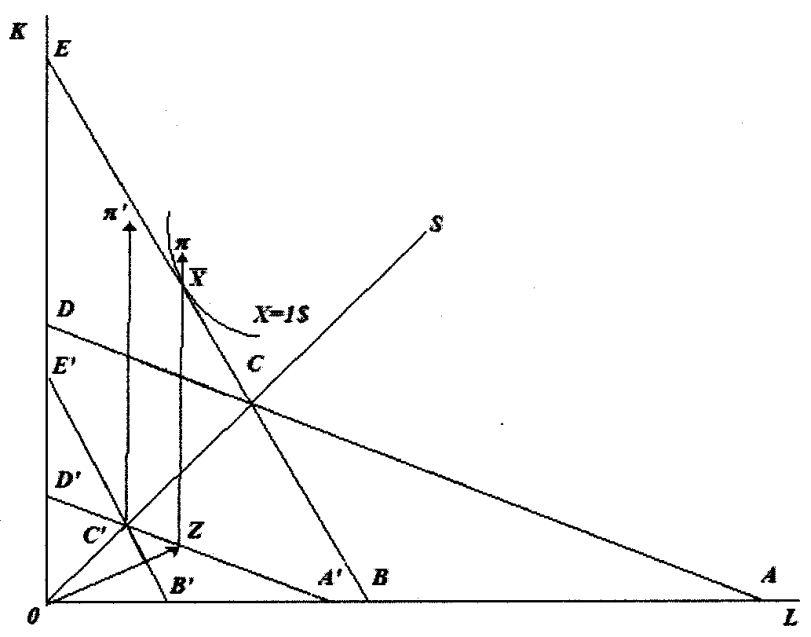

Gráfica 7.

En la Gráfica 7 se muestra el caso de una fragmentación costosa en términos de uso de factores, pero factible en costos monetarios. La construcción es similar a la Gráfica 6. En este caso, cuando uno de los fragmentos se produce en el país intensivo en trabajo, se ahorra lo suficiente para compensar el mayor uso de factores y puede utilizarse la tecnología fragmentada. El punto $\pi$ ' se encuentra debajo de la línea de isocosto original $E C B$.

Pero, ¿cuál es la relación entre la fragmentación y el precio de los factores? Supongamos que aquélla es cuantitativamente importante para afectar a los precios de los factores en los países. En estas circunstancias, ¿qué dirección tomarán dichos precios? Asimismo, demos por hecho que la situación inicial antes de la fragmentación es la que se muestra en la Gráfica 8. Los precios de los factores en el norte y en el sur con libre comercio están dados, como antes, por las líneas de isocostos unitarios de producción $B C E$ y $A C D$ respectivamente. Cada país o región está produciendo un número grande de bienes, las isocuantas de valor unitario se muestran y están etiquetadas simplemente como $Y_{1}, Y_{2}$, y así sucesiva- 


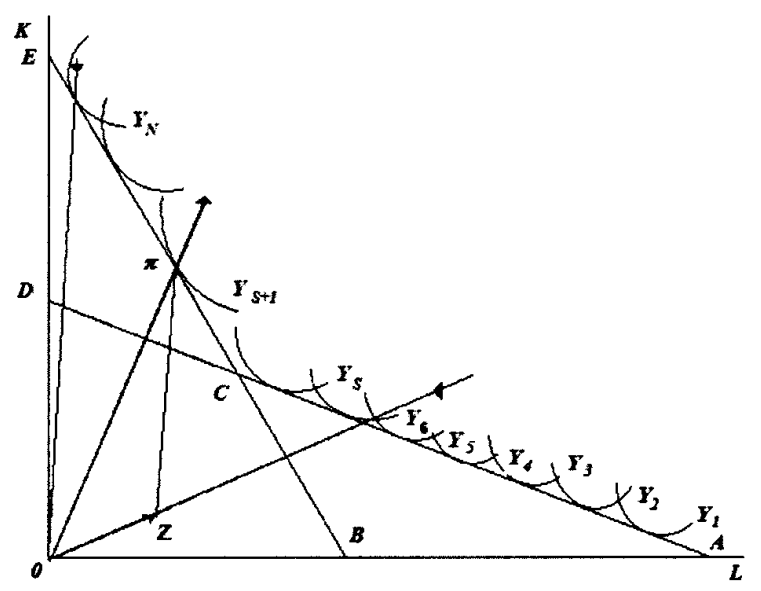

Gráfica 8.

mente. ${ }^{11}$ Consideremos que en el sur se elabora toda la producción para los bienes 1 hasta $Y_{S}$ y el norte produce el resto de lo bienes $Y_{S+1}$ hasta $Y_{N}$.

Supongamos ahora que la fragmentación se hace posible para uno de los bienes producidos en el norte, digamos el bien $Y_{S+1}$. Como antes, los factores requeridos de los fragmentos se representan con los vectores $0 Z$ y $Z \pi$. Puesto que $0 Z$ está en el Cono Sur y como estamos imaginando una separación no costosa, sabemos que la tecnología de fragmentación será usada.

Consideremos ahora la presión sobre los precios de los factores de esta nueva tecnología, representada por las flechas oscuras en la Gráfica 8, situadas por arriba de las líneas de isocosto de ambos países.

En la medida en que el sur comienza a producir el fragmento $O Z$, surgirán demandas adicionales para ambos factores en cantidades dadas por el vector $O Z$. Dichas demandas se suman a las de factores que el país tenía antes de la fragmentación para producir otros bienes. Esto tenderá a subir los precios de ambos factores empujando la curva de costo unitario hacia el origen, lo cual se indica con una flecha que apunta hacia el origen en dirección opuesta al vector $O Z$. ¿Cómo afectará esto a los precios relativos de los factores en el sur? Esto depende de la intensidad en el uso de los factores del bloque que se traslada hacia el sur, comparado con la intensidad de factores utilizada en la mezcla de producción en el sur antes de la fragmentación, lo cual analizaremos más adelante.

Mientras tanto, veamos qué sucede en el otro país. En el norte, donde el bien se producía en su totalidad y cuya tecnología está fragmentándose, suceden dos cosas. Primero, se suspende la producción del bien $Y_{S+1}$, reduciendo la demanda para ambos factores

11 En general, se puede suponer que algunos bienes se producirán en los dos países, pero aquí pensemos que eso no sucede.

\section{Desaarrollo}


en las proporciones antes empleadas. Esto, por sí solo, tenderá a reducir los precios de los factores y a empujar la línea de isocosto hacia arriba, por lo que dibujamos una flecha en dirección opuesta al origen y con la misma pendiente de $O Y_{S+1}$. Segundo, la nueva producción del fragmento $Z \pi$ requiere factores adicionales de acuerdo con la relación dada por la pendiente de esta línea. Por consiguiente, dibujamos una línea paralela a $Z \pi$ desde el origen hasta la otra flecha, en sentido contrario, que indica la presión existente sobre los precios de los factores que, a su vez, apunta hacia el origen donde se cruza la línea de isocosto para el norte. Estas flechas indican la manera en que se modificarán las líneas de isocosto y, por lo tanto, cómo se van a mover los precios de los factores por la fragmentación.

Las flechas que apuntan hacia dentro en la línea de isocosto del sur sugieren que los precios de ambos factores subirán y, puesto que la flecha está sobre la mitad del rango de las isocuantas usadas en el sur, la curva de isocosto se moverá de manera menos paralela, reduciéndose un poco la pendiente (bajando relativamente $w$ ). Por otro lado, si la flecha estuviera mucho más alejada — hacia la derecha en la línea de isocosto—, habría mayor incremento en la demanda de trabajo comparado con el capital y, por ende, en el precio del trabajo. Asimismo, elevarían la pendiente de la curva de isocosto como si se le empuja un poco hacia afuera desde la base por la presión de la flecha.

En el norte, la flecha que apunta hacia fuera sugiere precios descendentes de los factores. Debido a su posición — casi a la mitad del rango de las intensidades en capital de las industrias del norte-, hará que la línea de isocosto del norte se mueva hacia dentro de manera casi paralela. Al mismo tiempo, la flecha que apunta hacia dentro - para los fragmentos más intensivos en capital que se conservan en el norte- tiende a elevar los precios de los factores y a mover la línea de isocosto hacia dentro. Dado que el fragmento que permanece en el norte es más intensivo en capital que el promedio de la producción integrada, habrá una rotación que reducirá la pendiente para la línea $E C B$.

Para el caso ilustrado, las tres flechas juntas sugieren baja en los salarios relativos del sur (reducción en la relación salario-renta del capital) y también en los salarios relativos del norte (las nuevas líneas de isocosto se moverán un poco hacia dentro, lo cual indica una disminución en la pendiente y también en la relación salario-renta del capital). Es decir, en el país receptor del fragmento intensivo en mano de obra, la nueva tecnología tendría un efecto similar a la que discrimina contra el empleo.

En síntesis, en este caso particular, el cambio parece que nos lleva hacia la igualación de los precios de los factores, pero en un sentido negativo (los precios en los dos países se mueven en el mismo sentido), elevando las remuneraciones al capital y reduciendo los salarios en ambas naciones.

Si se acepta este argumento, el movimiento hacia la igualación de los precios como consecuencia de la fragmentación no está asegurado y puede ser negativo. El resultado 
neto depende de la posición de las flechas y, por lo tanto, en la intensidad de factores tanto de los fragmentos, como de la tecnología original. Existen muchas posibilidades, incluyendo aquella en que los precios relativos de los factores se mueven en la misma dirección o en sentido contrario en los dos países.

Por lo tanto, no está claro que según el modelo ortodoxo de comercio internacional la división de los fragmentos de producción entre naciones (de acuerdo con la dotación de factores de cada uno de ellos) lleve necesariamente a la igualación de los precios de los factores entre países.

En este orden de ideas, el planteamiento de que la reducción y eliminación de las barreras comerciales da lugar a una reducción de las disparidades económicas entre naciones, lo que podría transformar las condiciones que determinan los movimientos migratorios internacionales, aun en el modelo ortodoxo de comercio internacional, sólo es válido en condiciones especiales y no en general.

\section{La evolución de la maquila mexicana y remuneraciones a los factores: lo que sugieren los hechos}

Desde el inicio de las actividades maquiladoras, el gobierno mexicano esgrimió, como objetivo de largo plazo, la creación de vínculos entre la maquila y el resto de la economía, asumiendo un efecto de arrastre de la primera sobre la segunda, mediante la integración vertical progresiva de actividades en cadenas productivas, así como de factores productivos domésticos, valor agregado nacional y productividad crecientes, e intensificación de capital humano y tecnología. Por estas razones, el análisis de la maquila (y de la fragmentación en general) ha de considerar sus relaciones con el resto de la economía.

Expondremos brevemente algunos aspectos de la evolución de la maquila mexicana durante 1990-2000, para ilustrar su impacto en la economía nacional y en qué medida ha contribuido al limitado efecto de la apertura y de la expansión de las exportaciones manufactureras en el crecimiento del PIB y de los salarios. Sugerimos que para garantizar el avance de esta actividad tenía que ser no costosa, es decir, tenía que afectar el mercado de factores y mantener sus costos debajo de los países que compiten con México, y elevar la productividad por encima de otros proveedores. Los estímulos que alentaron la expansión de la maquila y el programa de internación temporal para las exportaciones (PITEx; éste y la maquila y concentran $87 \%$ del total de las ventas externas manufacturadas del país), instrumentados en México y en Estados Unidos, actuaban en contra de la integración del valor agregado mexicano y limitaron su margen para elevar la productividad. ${ }^{12}$ En vista

12 El gobierno mexicano estableció la exoneración de impuestos de importación a los insumos que se utilizarían en los bienes de exportación de la maquila y del PITEX, al tiempo que el gobierno estadounidense exoneró de los impuestos de importación al contenido estadounidense de los productos de la maquila mexicana y gravó el valor añadido en México.

\section{Desaarrollo}


de lo anterior, el impacto de la maquila en la economía nacional ha sido menor al esperado y parecería confirmar los argumentos que sugieren que este tipo de industrialización no necesariamente induce mayores niveles de productividad, empleo e ingresos.

Al finalizar el año 2000, el aporte de la maquila a la generación del PIB mexicano apenas superó $1.58 \%$, lo cual corresponde un avance de $0.04 \%$ del PIB al año, asumiendo que al inicio la maquila no aportaba nada al PIB. A partir de 1994 se registra un crecimiento importante de esta participación, que decae en 1999 y aún no se recupera (La Jornada, 7 de marzo de 2005). Así, la relación entre el incremento de las exportaciones de la maquila y su contribución al PIB mexicano es débil y se ha calculado que $1 \%$ de este crecimiento se ve reflejado en un aumento de $0.3 \%$ de su participación en el PIB (Puyama y Romero, 2005c).

La escasa incorporación de valor agregado nacional indica que no se han efectuado los encadenamientos ni creado los nexos entre la industria no maquiladora y la maquila; por esta razón, no hay vínculos entre la expansión de las exportaciones manufactureras y el peso de este sector en la generación del PIB. Efectivamente, la relación entre la ampliación de las exportaciones maquiladoras y el crecimiento de la participación de las manufacturas en el PIB es baja (un punto porcentual de crecimiento de aquellas contra 0.08 de expansión de esta última). Nuevamente, la regulación de la maquila y los PITEx impidió que se crearan los encadenamientos esperados. Las maquilas debían importar todos sus insumos para aprovechar la exención de impuestos y estuvieron obligadas, hasta 2001, a exportar el total de su producción, como medida de protección de la industria nacional. Las reformas introducidas por el TLCAN eliminaron esas restricciones (pero crearon otras) y la maquila se considera un establecimiento sometido a la regulación nacional y de dicho tratado. Tampoco podían abastecer la demanda de importaciones de otras maquiladoras mexicanas y esto dio origen a un comercio intraindustria. ${ }^{13}$ Las reformas introducidas por el TLCAN eliminaron esas restricciones. El tema futuro es cuál será el desarrollo de las manufacturas mexicanas, ¿hacia mayor fragmentación o hacia la integración vertical ascendente?

En el Cuadro 8 se presentan algunas variables del desempeño de la maquila y de la industria no maquiladora. ${ }^{14}$ En todas las variables anotadas hay un notable crecimiento, especialmente en el número de empleos (de 300 mil en 1988 a un millón 300 mil en 2000)

13 Puyana y Horbath (2005). Comercio intraindustria se define como el intercambio en doble vía, de productos clasificables en idéntica categoría arancelaría, cuya existencia se excluía en la maquila, pues los componentes que ingresan por una categoría, salen por otra al ser integrados en productos. El registro de este intercambio significa que hay maquiladoras que exportan los componentes que otras deben importar.

14 Presentamos los dos segmentos de las manufacturas, pues a raíz de los cambios introducidos por el TLCAN, a partir de 2001 se eliminaron prácticamente todos los estímulos y limitaciones que tenían los programas maquila PITEX, y se les sometió a los que norman todos los establecimientos permanentes mexicanos. 
LA MAQUILA (FRAGMENTACIÓN DE LOS PROCESOS PRODUCTIVOS) Y SU IMPACTO

Cuadro 8

México: indicadores y participación sectorial en la industria maquiladora de exportación

\begin{tabular}{|c|c|c|c|c|c|c|c|c|c|c|}
\hline \multicolumn{3}{|c|}{ No maq. Maquila } & No maq. & Maq. & No maq. & Maq. & No maq. & Maq. & No maq. & Maq. \\
\hline \multirow[t]{2}{*}{$A \tilde{n} o s$} & \multicolumn{2}{|c|}{ Ocupados } & \multicolumn{2}{|c|}{ Remuneraciones } & \multicolumn{2}{|c|}{ Valor agregado } & \multicolumn{2}{|c|}{$\begin{array}{c}\text { Remuneración } \\
\text { media }\end{array}$} & \multicolumn{2}{|c|}{$\begin{array}{c}\text { Productividad } \\
\text { media }\end{array}$} \\
\hline & Millones & $\begin{array}{l}\text { nes } \\
\text { onas }\end{array}$ & \multicolumn{4}{|c|}{ Millones de pesos de 1993} & \multicolumn{4}{|c|}{ Miles de pesos de 1993 por ocupado } \\
\hline \multicolumn{11}{|c|}{ Automotriz } \\
\hline 1988 & 0.27 & 0.07 & 7032 & 1360 & 16416 & 1746 & 26.26 & 18.50 & 61.31 & 23.75 \\
\hline 1993 & 0.35 & 0.10 & 9828 & 2059 & 25417 & 2686 & 28.24 & 19.93 & 73.03 & 26.01 \\
\hline 1995 & 0.32 & 0.12 & 7983 & 2390 & 23000 & 3199 & 24.73 & 19.79 & 71.25 & 26.49 \\
\hline 1999 & 0.46 & 0.19 & 11207 & 3936 & 40408 & 5005 & 24.27 & 20.27 & 87.52 & 25.77 \\
\hline 2000 & 0.50 & 0.22 & 13114 & 4688 & 47401 & 5469 & 26.18 & 21.72 & 94.62 & 25.33 \\
\hline \multicolumn{11}{|c|}{ Eléctrico y electrónico } \\
\hline 1988 & 0.25 & 0.13 & 4999 & 2291 & 8763 & 2843 & 19.72 & 18.10 & 34.56 & 22.46 \\
\hline 1993 & 0.29 & 0.16 & 6478 & 3015 & 11372 & 3670 & 22.16 & 19.32 & 38.90 & 23.51 \\
\hline 1995 & 0.31 & 0.19 & 6443 & 3569 & 12401 & 4574 & 21.11 & 18.83 & 40.63 & 24.13 \\
\hline 1999 & 0.49 & 0.33 & 10180 & 6633 & 23550 & 7787 & 20.66 & 19.97 & 47.79 & 23.44 \\
\hline 2000 & 0.57 & 0.39 & 12434 & 8366 & 27737 & 9297 & 22.00 & 21.57 & 49.08 & 23.97 \\
\hline \multicolumn{11}{|c|}{ Vestido } \\
\hline 1988 & 0.22 & 0.03 & 2393 & 296 & 6091 & 387 & 10.98 & 9.58 & 27.94 & 12.51 \\
\hline 1993 & 0.23 & 0.05 & 2902 & 538 & 7393 & 698 & 12.59 & 10.60 & 32.06 & 13.75 \\
\hline 1995 & 0.23 & 0.08 & 2450 & 812 & 7103 & 1156 & 10.52 & 10.07 & 30.49 & 14.33 \\
\hline 1999 & 0.39 & 0.22 & 3928 & 2243 & 9912 & 2961 & 9.96 & 10.09 & 25.14 & 13.33 \\
\hline 2000 & 0.42 & 0.25 & 4638 & 2728 & 10395 & 3386 & 10.96 & 10.94 & 24.57 & 13.58 \\
\hline \multicolumn{11}{|c|}{ Total } \\
\hline 1988 & 3.03 & 0.37 & 61575 & 6072 & 178416 & 7562 & 20.29 & 16.43 & 58.79 & 20.47 \\
\hline 1993 & 3.31 & 0.53 & 79694 & 9324 & 219934 & 11529 & 24.08 & 17.72 & 66.45 & 21.90 \\
\hline 1995 & 3.07 & 0.62 & 66625 & 10781 & 217582 & 14174 & 21.73 & 17.33 & 70.95 & 22.79 \\
\hline 1999 & 3.91 & 1.14 & 80482 & 19736 & 296631 & 24243 & 20.58 & 17.26 & 75.85 & 21.20 \\
\hline 2000 & 4.10 & 1.29 & 89853 & 24021 & 317092 & 27481 & 21.90 & 18.69 & 77.30 & 21.39 \\
\hline
\end{tabular}

Fuente: cálculos propios con base en información del SCNM, INEGI, Cuenta de Bienes y Servicios y La producción, salarios, empleo y productividad de la industria maquiladora de exportación 1988-2000 y $1996-2000$.

y en las remuneraciones. Es menor el crecimiento del valor agregado y de la productividad. Hay periodos en los cuales la maquila experimentó crecimiento extensivo, con mayor expansión del empleo que del valor agregado y, en ocasiones, aun las remuneraciones medias crecieron más que la productividad, sugiriendo que habría rigidez en el mercado laboral. Es importante anotar que, en ese periodo, el empleo en la industria manufacturera no maquiladora registró un crecimiento sustancialmente menor (de 33\%), con lo cual el 
empleo manufacturero en el total se mantuvo sin cambios. Por otra parte, las remuneraciones medias de la maquila crecieron $13.7 \%$ en el periodo, casi el doble que las manufacturas.

La maquila fue la generadora de empleo más dinámica del sector manufacturero total (una tasa de 333.3\% durante 1988-2000), con tasas de crecimiento superiores a las de la industria manufacturera. En 1988 representó 9.9\% del empleo manufacturero y $26.7 \%$ en 2000. La expansión del empleo maquilador se pudo realizar trasladando mano de obra desde actividades no manufactureras de menor productividad (es decir, absorbiendo trabajo no específico), o desde la manufactura misma, pero de actividades menos rentables que la maquila. También se pudo ocupar la mano de obra que se libera del traslado de segmentos intensivos en capital al exterior, resultante del conocido proceso de desintegración de las cadenas productivas y la pérdida de contenido nacional de la producción mexicana. En los dos primeros casos, habría aumentos en productividad total y de salarios, y en el tercero, el efecto podría ser o nulo o negativo.

El crecimiento del empleo en la maquila tendría tres efectos principales: crear puestos de trabajo que, en el caso de requerir trabajo no calificado y no específico a la manufactura, sería para personas desocupadas o vinculadas a actividades informales de inferior productividad e ingreso, o para los excedentes de mano de obra que arroja el sector agrícola. Se generaría un efecto de vent of surplus (Lewis, 1954) con ganancias netas para la economía, ya que se trasladaría el factor productivo redundante a actividades más productivas. Si el monto de la mano de obra requerida no altera el equilibrio del mercado, el salario no se elevaría de manera notable, aunque sí la productividad total de la economía y la participación del sector manufacturero en el empleo y en el PIB totales. Sería un caso de fragmentación no costosa, con límites determinados por los excedentes de la mano de obra trasladables sin alterar los costos de los productos.

Si la maquila demandara factor trabajo de la manufactura, habría traslado desde ésta a aquélla y el crecimiento neto del empleo sería menor y más reducidos los impactos sobre la productividad y los ingresos totales, aunque los salarios de la maquila serían mayores. No habría necesariamente una relación directa ni fuerte entre el crecimiento de las exportaciones de la maquila y la participación del empleo manufacturero ni del valor agregado en los totales. Probablemente tampoco se registraría una relación vigorosa entre la tasa de crecimiento de las exportaciones de maquila y la productividad del sector manufacturero total, ni las remuneraciones. En el caso de que se libere mano de obra por el ajuste en el sector manufacturero no maquilador, pueden presentarse dos situaciones: la primera, que la maquila acapara ese desempleo enrolando la mano de obra relativamente más calificada, con menor salario y en actividades de menor exigencia técnica; la segunda, que la maquila absorba la mano de obra menos calificada que se libera de la industria. En estas condiciones, el empleo total manufaturero no crecería. Y es lo que ha ocurrido, como se desprende de la muy baja relación entre el crecimiento de las exportaciones de maquila y 
el empleo manufacturero total: el crecimiento de un punto porcentual en las exportaciones maquiladoras se reflejaría en otro del 0.05 de peso del empleo manufacturero en el total. Estos datos reflejan el ajuste que realizó manufactura no maquiladora, en respuesta a las crisis y a los cambios en el entorno institucional: elevar la productividad por trabajador reduciendo el empleo (y manteniendo o incrementando la producción total), más que por nuevos aportes de capital por trabajador. En este caso, la maquila pudo absorber este empleo y expandir su participación en la ocupación total, sin que se elevaran los salarios. En estas condiciones se debería considerar que la fuente principal del trabajo para la maquila no fue el mercado laboral informal. Este supuesto parece corroborarse con la relación directa, y más significativa, entre las exportaciones de maquila y el empleo informal, en el sentido de que la expansión de las exportaciones de la maquila coincide con el crecimiento del peso del empleo informal, como porcentaje del empleo total. Esta trayectoria del empleo informal sugiere que la expansión de la producción y de las exportaciones de la IME no absorbieron la fuerza laboral desplazada de las manufacturas no maquiladoras, el empleo formal que generaron no tuvo la magnitud que permitiera reducir el peso de la informalidad en la ocupación total (véase Gráfica 9).

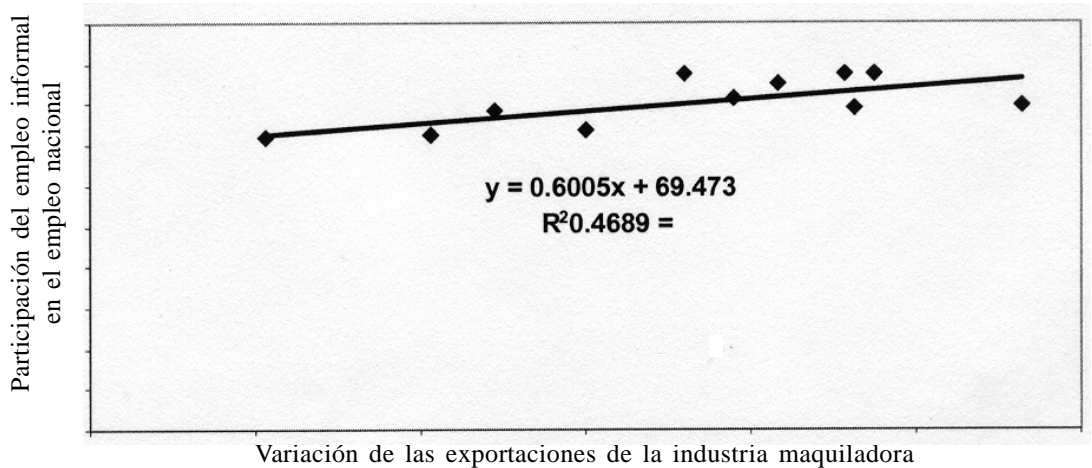

Gráfica 9.

Fuente: cálculos propios con base en INEGI, Sistema de Cuentas Nacionales, 1988-2001.

Como se ha explicado, los salarios pueden elevarse como resultado de ganancias sostenidas en productividad. Por los datos del Cuadro 8 y los análisis anteriores, es posible sugerir que el crecimiento de la productividad de la maquila fue limitado y muy inferior a la expansión de sus exportaciones y del empleo. En el año 2000 la productividad por trabajador alcanzó 21 mil pesos constantes de 1993 — un ascenso desde los 20 mil pesos registrados en 1989_, pero menor al nivel de 1993 y 1995, es decir, un crecimiento acumulado de $5 \%$ en 11 años. ${ }^{15}$ Un punto de crecimiento de las exportaciones de la maquila

15 Puyana y Romero (2005b) presentan un análisis detallado de la evolución productiva de la maquila total y en sus sectores más importantes, y la descomponen en los factores que contribuyen a su casi nulo crecimiento.

\section{Desaarrollo}


se relaciona con 0.01 de crecimiento de la productividad, lo cual corroboraría las conclusiones anteriores sobre el crecimiento extensivo que ha caracterizado a la maquila mexicana. Este resultado contrasta con la relación positiva y significativa de las exportaciones de maquila con la productividad manufacturera no maquiladora, explicada por el esfuerzo de ésta por incrementar su productividad para enfrentar la presión competitiva, como se sugiere en Puyana y Romero (2005c). La comparación de las dos tendencias podría avalar los supuestos del traslado de factores a actividades menos productivas, de menor valor agregado por trabajador, cuya incorporación fue frenada por la acción de los estímulos otorgados en los dos países. También lo explica la menor dotación de capital por trabajador.

Los límites al crecimiento de la productividad de la industria maquiladora están determinados por la influencia de los salarios sobre el valor agregado, relación que sugiere el costo unitario laboral. En la maquila, las remuneraciones representaron cerca de $74 \%$ del va en 1993, y $80 \%$ en 2000. Por lo tanto, sólo si se incrementa la productividad habría crecimiento del valor agregado en la maquila, sin aumento en el peso de los costos laborales en éste ni en los costos unitarios totales.

Una de las ventajas comparativas del país para atraer las actividades manufactureras que se trasladan por la fragmentación es la relación de las remuneraciones con la productividad. Los salarios bajos son el incentivo principal. Con el bajo impacto sobre el valor agregado, la baja productividad de la actividad maquiladora y el efecto en el mercado de trabajo - a pesar del gran del empleo-, no sorprende que sea igualmente limitado en las remuneraciones medias propias y las totales. Éstas debían contenerse para mantener la competitividad internacional. La abundancia de trabajo y la evolución del empleo en las manufacturas lo permitieron. En efecto, si bien las remuneraciones medias de la maquila ascendieron, el ritmo fue lento, aunque en momentos superior a la productividad (durante el periodo 1993-2000, por ejemplo) y sí acortó la distancia respecto de las remuneraciones medias de la manufactura no maquiladora. Las remuneraciones medias del sector maquilador representaron, en 1988, 80\% de las manufacturas, y en 2000, 86\%, evolución que se explica más por la desaceleración de éstas que por el ascenso de las primeras. Encontramos que la relación entre el crecimiento de las ventas de la maquila y el de las remuneraciones medias de la maquila y de la manufactura es negativo, muy débil en el primer caso y más fuerte en el segundo (Puyana y Romero, 2005c), lo cual explica el bajo impacto de las exportaciones en los salarios, que apuntamos en la primera sección de este trabajo.

\section{Conclusiones}

A la luz de estas reflexiones, la idea de que la fragmentación del proceso productivo (la maquila como parte de ella) ayudaría a elevar los salarios, a reducir el precio de la renta del capital en México y a inducir un movimiento en sentido contrario en Estados Unidos parece no tener fundamento.

\section{Dessarros perllo}


Este análisis es capaz de explicar claramente lo sucedido en México en años recientes, el auge espectacular de las exportaciones manufactureras, especialmente de las registradas en el régimen de maquila, así como el estancamiento (o disminución) de los salarios reales y el aumento a las remuneraciones reales al capital.

Hemos estudiado cómo la teoría no admite los encadenamientos que supuestamente emanarían de la maquila ni la disminución de las brechas en la remuneración a los factores. Tampoco permite el efecto directo de la apertura y el crecimiento económico sobre los ingresos. El debate continúa vigente. La exploración de las experiencias mexicanas, con la apertura y la maquila, puede esclarecer los resultados no concluyentes de numerosos estudios.

La maquila constituye un elemento central en la transformación de la estructura de la oferta externa mexicana y del crecimiento del coeficiente externo del PIB. La generación de empleo también ha sido importante, así como la contribución al equilibrio de la balanza comercial. No obstante, el avance del valor agregado nacional y de la productividad no han sido paralelos con las exportaciones.

Los resultados obtenidos permiten sugerir que se creó un esquema de fragmentación no costosa, el cual implica pocos avances en la generación de empleo manufacturero total $\mathrm{y}$ un efecto limitado sobre los ingresos. El poco avance de la productividad frena el crecimiento de los salarios, ya que su aumento alteraría los costos y anularía los estímulos a la expansión de la maquila.

La composición del valor agregado de la maquila (más de $80 \%$ en salarios) es otro freno al crecimiento de su productividad y a la expansión de su producción. Con esa estructura, si se ampliara la actividad, se distorsionaría el equilibrio del mercado al elevar los salarios. Reducir la participación de los salarios en el valor agregado sólo es factible elevando la dotación de capital. La competencia global en segmentos intensivos en mano de obra impone a México deprimir salarios, en caso de que no pueda atraer segmentos relativamente más intensivos en capital.

En estas condiciones, la evolución de las remuneraciones medias y de la productividad, así como la relación de estas variables con el crecimiento de las exportaciones y del empleo de la maquila, sugieren que la maquila mexicana no ha inducido — y probablemente no lo haría - incrementos significativos en los salarios ni la convergencia con la remuneración a los factores de Estados Unidos, y que en México se han presentado, a la fecha, los efectos de tecnologías intensivas en capital que ahorran trabajo.

\section{DeSaarrollo}




\section{Bibliografía}

Arndt, Sven W. y Henryk Kierzkowski, "Introduction", en Sven W. Arndt y Henryk Kierzkowski, Fragmentation: New Production Patterns in The World Economy, 2001.

Coatsworth, John H., Los orígenes del atraso, México, Alianza Editorial Mexicana, 1990.

Deardoff, Alan V., "Fragmentation Across Cones", en Sven W. Arndt y Henryk Kierzkowski, Fragmentation: New Production Patterns in The World Economy, 2001.

La Jornada, 7 de marzo de 2005.

Lewis, W.A., "Economic Development, with Unlimited Supplies of Labour", en Theodore Morgan, George W. Betzy N.K. Choudhry, Readings in Economic Development, Wadsworth, 1963.

Loertscher, R. y Wolter, F., "Review of Grubel and Lloyd (1975)", en Weltwirtschaftliches Archiv, vol. 116, 1980, pp. 281-293

Reforma, 11 de octubre de 2000

Puyana, Alicia y José Romero, "La convergencia económica y los acuerdos de integración. ¿Hay enseñanzas del TLCAN para el ALCA?", en Luis A. y J.A. Calva, La economía mexicana en el décimo año de operación del TLCAN. Estrategias, desempeño, balance del TLCAN y alternativas, $2005 \mathrm{a}$.

, "Las exportaciones de maquila y la productividad manufacturera durante el periodo post- reformas: 1988-2000”, en A. Puyana (editora), La maquila mexicana. Enfrentando los retos de la globalización, FLACSO, en imprenta, 2005 b.

, "Hacia una evaluación de los efectos multiplicadores de la actividad maquiladora", en dictaminación, Centro de Estudios Sociales, COLMEX, 2005c.

, "The Mexican agricultural and Livestock Sector: Ten Years Living with NAFTA Unequal Economies, Asymmetric Negotiations and Foreseeable Results", ponencia presentada en el seminario "North American Incomes and Productivity in the Global Context: Industry Challenges", Comission for Labour Cooperation and the Carnegie Endowment for Internacional Peace, Washington, 22 de octubre de 2004.

Puyana A. y Horbath, "Margen de sustitución de importaciones de los sectores manufactureros no maquilador y maquilador", en A. Puyana (editora), La maquila mexicana. Enfrentando los retos de la globalización, FLACSO, en imprenta, 2005.

Tuirán, R.; Virgilio Partida y José Luis Ávila, "Crecimiento económico, libre comercio y migración”, en Migración México-Estados Unidos, presente y futuro, México, CONAPO, 2000.

Weintraub, Sidney, A Marriage of Convenience, Oxford University Press, 1990. 